\title{
O EREMITÉRIO DO CRUSTÁCEO: SOBRE "MARY BENEDITA", CONTO DE CONCEIÇÃO EVARISTO, E A ARTE COMO MEIO DE SER
}

\author{
Henrique Furtado de Melo (UEL PPGL - mestrando bolsista CNPQ) \\ furtado.henrique@live.com
}

\section{RESUMO}

Como fragmento de nossa pesquisa em torno da obra em prosa de Conceição Evaristo, trazemos parte de nossos mapas para este trabalho. Tendo como centro reflexivo o conto "Mary Benedita", publicado no livro "Insubmissas Lágrimas de Mulheres" (2011), traçamos um percurso de leitura que destaca a importância do impulso criativo como meio de suportar a dor e criar um espaço para ser através da arte. Nossa pesquisa tem como foco grafar mapas de caminhos por entre as obras de Evaristo, apontando os meios pelos quais tanto as personagens ou narradores, quanto a própria autora constroem mundos por sobre ruínas de violência e exclusão, inventando caminhos de ser e suportar a dor por meio da arte de narrar e compartilhar. Conceição Evaristo, através do contar, cria possibilidades de retomada de poder sobre meios de produção de memórias, subjetividades, devires, em especial negros e femininos. Como bases teóricas que transpassam por nossas leituras, destacamos Deleuze, Guattari, Michèle Petit, Winnicott, e os próprios ensaios e entrevistas de Evaristo.

\section{INTRODUÇÃO}

Este trabalho apresenta um fragmento de nossas reflexões de mestrado, que articulam experiências de campo realizadas no âmbito da esfera carcerária do Estado do Paraná aliadas a nosso percurso de leitura da obra de Conceição Evaristo. Procuramos traçar mapas por entre as narrativas da autora, construindo modos de compreender a escrevivência evaristiana como recurso emancipatório do corpo negro. Através de nosso percurso pelas experiências de campo, encontramos sujeitos que constroem, a partir de meios escassos, caminhos de emancipação através da expressão e do compartilhamento expressivo. Dessa forma, as duas etapas de nossos trabalhos se unem na perspectiva de compreender essa emancipação pela criação, tanto na obra de Evaristo, quanto nas produções dos rapazes apenados.

O presente texto inicia-se com uma leitura imersiva, característica de nosso modo de trabalho, seguindo por reflexões articulando as duas etapas de pesquisa referidas acima a reflexões teóricas. O resultado, neste artigo, é, repetimos, fragmento de nossos trabalhos de mestrado. Sendo assim, devemos dizer que há apontamentos que se desdobram ao longo de outros fragmentos que não cabem no espaço desse artigo.

\section{CORPO-ARTE: "MARY BENEDITA"}

Mary Benedita procurou pela ouvinte, encontrando nos ouvidos dela um pouco de si própria, um impulso para lançar a voz, "oferecer o seu corpo/história" (EVARISTO, 2011, p. 59). Como a voz é muito grande, e não cabe na própria língua, 


\section{SEMINÁRIO DE PESQUISA EM CIÊNCIAS HUMANAS - SEPECH \\ Humanidades, Estado e desafios didático-científicos \\ Londrina, 27 a 29 de julho de 2016}

Mary aprende os falares de outros idiomas, mistura as palavras, estende o corpo por sobre terras de muitos cantos.

"My sister, quem tem os olhos fundos, começa a chorar cedo e madruga antes do sol para secar sozinha as lágrimas” (EVARISTO, 2011, p. 60), e por isso é preciso correr, imprimir urgência sobre os passos, escalar o tempo como se o chão pudesse fugir de sob os pés. E quando parece quieta, extasiada, Mary Benedita, na verdade, contempla o Mapa Mundi, na ânsia de engolir o mundo com o próprio corpo (EVARISTO, 2011, p. 61), tomar posse da miniatura como meio de mover-se e marcarse pela imaginação, pela ficcionalização.

Como "queria mais chão e mais céus do que" (EVARISTO, 2011, p. 62) via na pequena cidade de Manhãs Azuis ao lado de seus pais pequenos lavradores e de seus muitos irmãos, na infância a menina fingira doença, lentidão entartarugada, vitalidade engolida pelo desejo de mundo. Tia Aurora, da cidade grande, capital Horizonte Aberto, aceitara-lhe em sua casa.

Com o apoio da tia, a menina foi conseguindo convencer os pais a continuar na capital. Salta à voz o globo terrestre no quarto de Aurora, a miniatura por qual Mary pode agarrar o mundo com as mãos, um modo de conter o rio-tempo entre os dedos em concha, torna-lo narrativa, parte do próprio corpo.

Mas além do globo, no quarto também há um violino. Marca da marca. Por meio dele é possivel construir fragmentos de sons isolados, algo que se destaca no mundo sonoro e produz rachadura no espaço, música. Assim como o globo terrestre, o violino traz em si a potência de um passo na construção de territórios.

Da alma do violino pode nascer marca, ruga no plano sonoro, expressão. É preciso expressão para que haja terra, é preciso desvio para criar ritmo e ritmo para dimensionar o mundo. É por isso que o quarto de Aurora traz um mundo em potencial, carrega terra possível para Mary Benedita. Assim, a menina mergulha na pulsão, no devir-expressivo, na arte em potência. E aos poucos funde-se a esses novos fragmentos, cria novas possibilidades ${ }^{l}$.

Mas não é só em Aurora que a menina encontra impulso. Na memória da terra antiga, nas cores do ambiente em que nasceu, nas frutas, animais, insetos, do solo, nas tintas artesanais feitas pelas mulheres da família desde os tempos de África, na ancestralidade, na VOZ DO GRIÔ que segue contando as vidas de todas essas mulheres, também Mary Benedita encontrou fragmentos para montar seu mosaico-mundo.

Misturando as cores do quarto de Aurora, da própria infância e ancestralidade, e experiências corporais intensas, Mary mergulha num movimento artístico que resulta na sua projeção como pintora. Entretanto há algo mais que nasce dela. Há algo que

\footnotetext{
1 “O território não é primeiro em relação à marca qualitativa, é a marca que faz o território. As funções num território não são primeiras, elas supõem antes uma expressividade que faz território. É bem nesse sentido que o território e as funções que nele se exercem são produtos da territorialização. A territorialização é o ato do ritmo tornado expressivo, ou dos componentes de meios tornados qualitativos. A marcação de um território é dimensional, mas não é uma medida, é um ritmo. [...] No seio do território, há inúmeras reorganizações, que afetam tanto a sexualidade, como a caça, etc.; há até mesmo novas funções, como construir um domicílio. Mas essas funções só são organizadas ou criadas enquanto territorializadas, e não o inverso. O fator $\mathrm{T}$, fator territorializante, deve ser buscado em outro lugar: precisamente no devir-expressivo do ritmo ou da melodia, isto é, na emergência de qualidades próprias (cor, odor, som, silhueta...).

Podemos chamar de Arte esse devir, essa emergência? O território seria o efeito da arte" (DELEUZE \& GUATTARI, 1997, p. 122-123).
} 


\section{SEMINÁRIO DE PESQUISA EM CIÊNCIAS HUMANAS - SEPECH \\ Humanidades, Estado e desafios didático-científicos \\ Londrina, 27 a 29 de julho de 2016}

precisa transbordar do corpo, há corpo que precisa transbordar-se. E de navalhar-se, vale-se, e marca, ao mesmo tempo, o corpo com a arte e a arte com o corpo, pinta com o sangue, e risca-se com a lâmina. Faz jorrar de si o impulso de criar, a correria de engolir o mundo, a pressa de ser, e também faz marcar no rosto, na pele, o ser de si.

Enquanto Mary Benedita conta e expõe as molduras em torno de seu corpo, a ouvinte seca os olhos no gozo da escuta (EVARISTO, 2011, p.9), sente as ardências e dores da navalha, mistura a voz, pois que é ouvinte e contadora ao mesmo tempo, é uma e é outra, as vozes se misturam na narração e na pele e no corte e no sangue e na arte de uma a outra se encontra. E é ela, mas sou eu - e a terra que se faz num corpo se faz no outro.

Carrego terra em mim, para que não me falte aos pés quando salto "se for preciso, tomarei o território em meu próprio corpo, territorializo meu corpo: a casa da tartaruga o eremitério do crustáceo, mas também todas as tatuagens que fazem do corpo um território" (DELEUZE \& GUATTARI, 1997, p. 128), todas as cicatrizes que fazem do meu corpo tela.

\section{MEMÓRIA - O EREMITÉRIO DO CRUSTÁCEO}

Mary Benedita segura o globo terrestre nas mãos e mergulha no aprendizado de diversas línguas. Precisa engolir o mundo e espalhar o corpo por quanto chão puder. É um modo de dominar o mundo a partir da miniatura, de "resistir à dissolução do ambiente" . Os rapazes da penitenciária encontraram seus modos de empreender movimento semelhante. Feito Carolina Maria de Jesus, que preenchia até as bordas os cadernos velhos que encontrava no lixo, Dajan ${ }^{3}$ também marcava seu corpo em todo espaço vago de folha. Se a penitenciária é a margem, as galerias de segurança, onde Dajan residia, são margem da margem, mas ele sabia muito bem ocupar as bordas.

Enquanto Mary Benedita, com a navalha, faz do próprio corpo escultura, e dos quadros si mesma, Kadiri junta o que pode e levanta sobre folhas de sulfite esculturas de sabonete, totens, flores, mundos em miniatura circundados por desenhos a lápis de cor. As esculturas de Kadiri são como lembrança/produção da própria humanidade que, segundo a palavra de ordem, ficou do lado de fora da muralha do cárcere.

A marca no papel, no quadro, no corpo, é memória de si, movimento expressivo que cria, ao mesmo tempo, território e inspiração territorializante. É navalhando o próprio corpo que Mary Benedita, simultaneamente, reconhece-o e cria-o como lar, morada, eu-corpo, território ${ }^{4}$. Cada um a sua forma, os rapazes apenados encontravam,

\footnotetext{
2 "Fico mais à vontade nos mundos da miniatura. São para mim mundos dominados. Vivendo-os, sinto partir de meu ser sonhador ondas mundificadoras. A enormidade do mundo é para mim apenas emaranhamento das ondas mundificadoras. A miniatura sinceramente vivenciada desprende-me do mundo ambiente, ajuda-me a resistir à dissolução do ambiente" (BACHELARD, 1989, p. 168, grifo nosso).

3 Os nomes utilizados para referenciar os apenados são fictícios, para efeito de preservação de suas identidades.

4 “'O expressivo é primeiro em relação ao possessivo, as qualidades expressivas ou matérias de expressão são forçosamente apropriativas, e constituem um ter mais profundo que o ser. Não no sentido em que essas qualidades pertenceriam a um sujeito, mas no sentido em que elas desenham um território que pertencerá ao sujeito que as traz consigo ou que as produz. Essas qualidades são assinaturas, mas a assinatura, o nome próprio, não é a marca constituída de um sujeito, é a marca constituinte de um
} 


\section{SEMINÁRIO DE PESQUISA EM CIÊNCIAS HUMANAS - SEPECH \\ Humanidades, Estado e desafios didático-científicos \\ Londrina, 27 a 29 de julho de 2016}

também, outros modos de criar um espaço por onde escorrer o corpo que não cabia nos cubículos, um meio de evitar a mutilação de deixar-se encaixar na fôrma da produção de subjetividade em massa de detentos. É importante observar o movimento expressivo empreendido pelos apenados e a forma como esse movimento acaba surgindo nas produções textuais deles, como, citando Benjamin (1987, p. 205), a marca da mão do oleiro impressa na argila do vaso. É a partir dessa marca do nosso corpo que fica nas coisas que algo vai se construindo, um espaço, um mundo de dentro-fora.

Mary Benedita toma a arte com as mãos e espalha o próprio sangue por telas, risca a própria pele, sobrepõe ao corpo-biológico um corpo-morada. E a sua ouvinte toma seu corpo no dela, funde as vozes-rios em narrativa-foz. Destacamos as marcas expressivas que aparecem tanto nas produções escritas ou nas diversas manifestações artísticas realizadas pelos apenados atendidos durante o projeto realizado na esfera carcerária, quanto nas personagens de Conceição Evaristo, pois que é a partir dessas marcas que a roda das (re/des)territorializações põe-se em curso. Mas há um outro ponto a que devemos nos atentar, e que nos será importante em seguida: a maneira como essas movimentações expressivas funcionam, ao mesmo tempo, como rugido que demarca meu espaço, e como dança que convida o outro a entrar.

\section{1}

Num dos trabalhos que realizamos com os apenados, reunimo-nos em torno da obra de Vinicius de Moraes. A proposta deu-se a partir da exibição do documentário biográfico Vinicius (2005), de Miguel Faria Junior, como forma de introduzir os leitores numa ambiência poética, favorecida pelo ponto de vista do roteiro, que vincula vida afetiva e poesia como elementos constituintes de uma mesma experiência autoral. Em seguida, os rapazes foram convidados a ler a coletânea de poemas para, por fim, escreverem livremente a respeito de um ou mais poemas por eles escolhidos ${ }^{5}$. Seguiremos com algumas reflexões a partir do que construímos com um dos rapazes, durante o trabalho.

Com um incentivo e um caderno, Akins passou a escrever o que sentia nas horas de desespero. Quando o corpo era grande demais dançava, jogava capoeira, cantava, inventava história, lia e relia. O caderno foi mais um espaço para pôr uns bons pedaços de si quando o chão era pouco para dançar ou cantar, e quando não havia ouvido por onde entrar suas histórias.

Akins juntava textos diversos entre as capas do caderno, como quem agrupa partes de si num espaço contornado. Petit (2009, p. 140-143), a respeito do uso de cadernos de notas por adolescentes em diversos países, reflete sobre como os textos que esses jovens copiam ou criam, com palavras ou desenhos, quando agrupados num

domínio, de uma morada. A assinatura não é a indicação de uma pessoa, é a formação aleatória de um domínio. As moradas têm nomes próprios e são inspiradas. "Os inspirados e sua morada...", mas é com a morada que surge a inspiração. É ao mesmo tempo que gosto de uma cor, e que faço dela meu estandarte ou minha placa" (DELEUZE \& GUATTARI, 1997, p. 123).

5 As análises e reflexões apresentadas em torno do referido trabalho encontram-se, de maneira mais aprofundada e centralizada, nos artigos $A$ leitura literária como revivência e ressignificação subjetiva de um aluno-detento (LIMA \& MELO, 2013) e Leitura literária e vivência criativa no espaço carcerário (LIMA \& MELO, 2016), publicados, respectivamente, na Revista Conexão UEPG e Via Atlântica (USP). 


\section{SEMINÁRIO DE PESQUISA EM CIÊNCIAS HUMANAS - SEPECH \\ Humanidades, Estado e desafios didático-científicos \\ Londrina, 27 a 29 de julho de 2016}

caderno, parecem servir como forma de dar contorno ao que eles são. As capas, as folhas pregadas, os textos reunidos, tudo conduz a uma unidade que, ainda que não circunde, por completo, tudo aquilo que eles são, confere certa coesão e estabilidade a um espaço no qual podem desaguar parte daquilo de si que não cabe em si.

Akins vale-se do caderno de forma semelhante, agrupando poemas de que gostou, trechos de canções, declarações de amor, cartas, desenhos, recortes de estrelas e corações coloridos colados, decorações feitas a lápis de cor. Notamos que, assim como relata Michèle Petit a respeito dos trabalhos acompanhados por ela, Akins apropria-se de uma série de textos de outros autores, como forma de usá-los para expressar aquilo para que lhe faltam palavras.

A partir do trabalho em torno da obra de Vinícius de Moraes, Akins registra em seu caderno o poema "Janelas Abertas". Perguntado sobre o porquê da escolha, não soube responder. Todavia ressaltou: "Pra fazer o texto do filme eu escolhi outro, mas foi deste aqui que eu gostei mais". É um modo de guardar seu espaço, expor uma parte de si, mas construir/conservar um lugar íntimo de ser ${ }^{6}$.

Para o texto livre escrito após as leituras, Akins escolheu o poema "Epitáfio", como vemos a seguir:

O epitáfio de Vinicios e espirado nele mesmo Aqui jas o sol que criou a aurora e deu a luz ao dia e aplascentou a tarde $\mathrm{O}$ mágico pastor de mãos luminosas que fecumdou as rosas e as despetalou. Vinicios era como um pastor de literatura que cultiva poema e colhe poesia que exala palavras, palavras que mechem com nossos coração e trás lágrimas, lágrimas gostosas. Vinicios eu poeta que nem se emportava com riquezas, ganância uma palavra que conhecia, mais já mais exercitará (Transcrição de fragmentos da produção textual de Akins).

Nesse fragmento, é possível observar um processo de apropriação de recursos específicos do gênero lírico, como: metáforas - "Pastor de literatura"; "cultiva poema e colhe poesia que exala palavras" - comparação - "Vinicios era como um pastor" -, anáfora e paralelismo - "exala palavras, palavras que mechem com nossos coração e trás lágrimas, lágrimas gostosas". Ainda que de forma estruturalmente simples, Akins procura, em seu texto, aproximar-se do fazer poético, o qual está intimamente ligado a uma linguagem marcada pela emergência do Eu. O enunciado "Vinicios eu poeta que nem se emportava com riquezas, ganância uma palavra que conhecia, mais já mais exercitará.", apresenta um deslize ortográfico, ausente nas demais produções de Akins O suposto erro resulta da aglutinação do verbo ser flexionado no presente do indicativo (é) - e não acentuado graficamente (e) - com o artigo indefinido no singular (um) - cuja apócope do $\mathrm{m}(\mathrm{u})$ demarca forte influência da oralidade -, resultando na inscrição "eu".

Como observamos em artigo para a Revista Via Atlântica (USP):

\footnotetext{
${ }^{6}$ A cópia, longe do exercício escolar, não é senão uma submissão aparente; docilidade astuta, ela permite se apoderar do texto, incorporar essa força que oprime o leitor comum, aquele que se contenta, às suas custas, em ler. É portanto escrevendo que se conjura o malefício do livro". Fabre formula a hipótese de que a cópia teria, assim, um lugar central nas práticas populares de apropriação da escrita — o que se verifica facilmente em muitas épocas, muitos países, e se confirma também no que observei (PETIT, 2009, p. 136).
} 


\section{SEMINÁRIO DE PESQUISA EM CIÊNCIAS HUMANAS - SEPECH \\ Humanidades, Estado e desafios didático-científicos \\ Londrina, 27 a 29 de julho de 2016}

O aparente erro ortográfico pareceu-nos a manifestação do desejo de $A$ [Akins] em estar mais próximo do poeta e mais apropriado do seu lugar de ser. "Vinicios eu poeta" representa a inscrição do deslocamento subjetivo, na medida em que cria um novo lugar para $A$, entre Vinicius e poeta, mergulhado na poesia, momentaneamente suspenso do cárcere (LIMA \& MELO, 2015, p. 307).

Os trabalhos que realizamos com Akins e todos os outros rapazes que atendemos na penitenciária nos ajudaram a pensar o espaço, o corpo e a expressão dentro da relação que passamos a investigar, de arte como meio de ser e resistir ao mundo, em especial em situações de sofrimento. Quando passamos a transitar pela obra de Conceição Evaristo, percebemos como sua obra traz contribuições importantes a essa investigação, bem como essa pesquisa pode trazer, também, boas reflexões sobre a escrita da autora.

Akins preenche um diário com seu corpo, coloca mesmo aquilo de si que nem sabe por que faz parte de si. Em seu texto sobre Vinicius de Moraes, mergulha na poesia, nasce "eu" entre os poetas, intercala o próprio corpo ao do poeta, mistura as vozes, faz da folha um espaço poético onde estar, em suspensão, içado do cárcere e autor(izado) a falar e criar. Conceição Evaristo imprime em suas personagens movimentos semelhantes, de construção de espaços para ser.

2.2

Carolina Maria de Jesus exerce grande influência sobre a formação de Conceição Evaristo, sendo inclusive citada em artigo publicado em 2005 pela revista Mulheres no Mundo: "Não se pode esquecer, jamais, o movimento executado pelas mãos catadoras de papel, as de Carolina Maria de Jesus, que audaciosamente reciclando a miséria de seu cotidiano, inventaram para si um desconcertante papel de escritora."

Tomemos então um trecho de Quarto de Despejo (1960), sua obra mais conhecida até o momento, no andamento de nossas reflexões:

Enquanto escrevo vou pensando que resido num castelo cor de ouro que reluz na luz do sol. Que as janelas são de prata e as luzes de brilhantes. Que a minha vista circula no jardim e eu contemplo as flores de todas as qualidades. (...) É preciso criar esse ambiente de fantasia para esquecer que estou na favela (JESUS, 1960, p. 60, grifo nosso).

Carolina Maria de Jesus resiste, pela arte e na arte, Conceição Evaristo também:

$\mathrm{Na}$ escola adorava redações tipo: "onde passei as minhas férias", ou ainda, "Um passeio à fazenda do meu tio", como também "A festa de meu aniversário" A limitação do espaço físico e a pobreza econômica em que vivíamos eram rompidas por uma ficção inocente, único meio possível que me era apresentado para escrever os meus sonhos.

Ler foi também um exercício prazeroso vital, um meio de suportar o mundo, principalmente adolescência, quando percebi melhor os limites que me eram impostos" (EVARISTO, 2005, p.201, grifo nosso).

Sobre os jovens de um dos trabalhos observados por Michèle Petit, ela afirma: 


\section{SEMINÁRIO DE PESQUISA EM CIÊNCIAS HUMANAS - SEPECH \\ Humanidades, Estado e desafios didático-científicos \\ Londrina, 27 a 29 de julho de 2016}

Eles não economizam meios, não economizam textos - ou, às vezes, imagens - capazes de abrir o horizonte para resistir ao confinamento, aos constrangimentos e às eventuais tentativas dos poderes - políticos, simbólicos ou domésticos - de entravar, estreitar e controlar seus movimentos. Eles se esforçam para salvaguardar um conhecimento próprio e do mundo, para preservar frente e contra tudo um espaço de pensamento, uma dignidade e uma parte de liberdade, de sonho, de inesperado (PETIT, 2009, p. 289, grifos nossos).

Resistir é manter-se de pé, cravar-se num espaço; seja tangível ou ficcional. E, em verdade, não há bem uma fronteira demarcada entre o tangível e o ficcional, eles se misturam, se confundem. Como vemos há uma constante referência ao espaço, ao movimento, ao estreitamento e controle do corpo, bem como à revolta contra esse controle, revolta expressiva, de água que uma hora acaba escorrendo pelas frestas.

Petit relata o caso de Mira Rothenberg, levada a dar aulas a trinta e duas crianças provenientes da Europa Central pós Segunda Guerra Mundial. Nascidas nos campos de concentração ou abandonadas pelos pais para que sobrevivessem, essas crianças demonstravam profunda e recorrente desconfiança, construíram fortalezas em torno de si, para protegerem-se dos horrores por que passaram:

Rothenberg, aproveitando uma pausa nos ataques de raiva, contou-lhes sobre os índios da América:

"Contei para eles como aqueles homens aos quais o país pertencia tornaram-se refugiados na sua própria terra, da qual foram privados. Encontrei um livro de poemas dos índios que falava da terra que eles amavam, dos animais com os quais viviam, de sua força, de seu amor, de sua raiva e seu orgulho. E de sua liberdade.

As crianças reagiram. Alguma coisa havia mexido com elas. Os índios deveriam sentir pela América o mesmo que elas por seus países de origem.

E nós nos transformamos em índios. Tiramos os móveis da classe. Instalamos tendas e pintamos um rio no assoalho. Construimos canoas $e$ animais de tamanho natural em papel machê. [...] As crianças começaram a se desvencilhar de suas carapaças. Nós morávamos nas tendas. Comíamos ali. Elas não queriam mais voltar para suas casas" (PETIT, 2009, p.69-70, grifos nossos).

No relato de Rothenberg é possível notar a importância do espaço, e mais: do espaço (re)inventado, adensado pelo ficcional. Quando surge a fissura no "real", encontrada pelas crianças na voz da professora ao contar a história dos índios e ao ler poemas deles, nos quais elas parecem ter sido capazes de se ver, o espaço se confunde, e as crianças colocam-se em cena, assumem vozes autorais na (re)composição de um lugar para ser. É preciso resistir para reexistir, é preciso cravar os pés nessa "própria terra", como a que os índios e as crianças perderam, para, então, retomar o poder de narrar-se.

Para Conceição Evaristo escreviver é "um modo de ferir o silêncio imposto (...) [é] o movimento de dança-canto que o meu corpo não executa. ", ao escreviver-se "toma-se o lugar da escrita, como direito, assim como se toma o lugar da vida" (EVARISTO, 2005, p.202). Que lugar da vida seria esse ao que se refere a autora, 


\section{SEMINÁRIO DE PESQUISA EM CIÊNCIAS HUMANAS - SEPECH \\ Humanidades, Estado e desafios didático-científicos \\ Londrina, 27 a 29 de julho de 2016}

senão o lugar daquela/daquele que, nas palavras de Zumthor (2007, p. 41): consegue vislumbrar, pela fissura no "real", a alteridade e colocar-se em cena como sujeito, para que, então, possa narrar e narrar-se, abrindo outras possibilidades de ser?

Nesse sentido, a criação, seja escrevivente, seja de tantos outros modos, em letras, pensamentos, audição, dança, canto, culinária, reconto, ... funciona como grunhido, rugido que marca o mundo e faz muro por onde o outro não deve passar, registra aquilo que sou no chão que é meu. Mas em seguida queremos nos atentar a um outro aspecto da movimentação do impulso criativo.

\section{3}

Christian Larson, em vídeo (2013) ${ }^{7}$ para "Mystery Film Experiment", um processo criativo coletivo organizado pela banda islandesa Sigur Rós, em referência ao álbum "Valtari" (SIGUR RÓS, 2012), apresenta duas pessoas que se encontram num prédio em ruínas. Uma dança com traços animalescos começa sendo feita por aquela que parece morar nas ruínas. A segunda pessoa chega e a encontra, parando também de forma animalesca para assisti-la de longe. Um grande fosso separa as duas. Mas a dança parece um convite: "entre, é a minha casa, mas pode ser nossa, você pode ser eu, podemos nos conjugar no plural". Em devir-animal os dois corpos se aproximam e se misturam. Cada um devem-outro. E então são oito patas que se contorcem e produzem um ser múltiplo num só corpo. Grunho para marcar o limite por onde o outro não deve passar, danço para convidá-lo a entrar.

Falamos, então, de sedução. Jovens acompanhados por Michèle Petit apropriamse de poemas alheios para oferecerem às suas noivas. Reconhecem haver algo de forte naquelas letras, algo que também os seduz a ponto de precisarem tornar aquilo parte deles.

Insubmissas Lágrimas de Mulheres (2011) traz uma linha importante que transpassa as narrativas que compõem o livro: uma ouvinte que se torna narradora uma mulher que se apropria das histórias e corpos alheios. Esse movimento, de deixarse seduzir pelo outro que dança-canta, surge como estrutura fundamental da escrevivência. É deixando-se seduzir pela voz das outras que a ouvinte das histórias se torna narradora delas, uma narradora múltipla, assim como as personagens do vídeo de Larson a que nos referimos - há uma fusão de corpos.

Ao longo dos trabalhos que realizamos na penitenciária, a cada vez que líamos uma entrada de diário, ouvíamos uma história de vida que deslizava por um conto que líamos juntos, víamos um desenho, ouvíamos um desabafo, um agradecimento ou nos deparávamos com papeis cheios de uma liberdade paradoxalmente paralela ao cárcere, encontrávamos uma coisa que não sabíamos muito bem como nomear.

Com o amadurecer das ideias e um afastamento do trabalho, entendemos melhor. Na poesia, no conto, na arte que liam, os rapazes encontravam um pouco de si, uma palavra, uma imagem, um lugar onde pôr um sentimento sem nome. Na leitura dos \{rapazes lendo\} encontrávamos outra poesia. Poesia da poesia, conto do conto, sobrearte. E no espaço entre o texto e o corpo (se é que há algum), nos encontramos por

${ }^{7}$ http://sigur-ros.co.uk/valtari/videos/valtari-larson/ 


\section{SEMINÁRIO DE PESQUISA EM CIÊNCIAS HUMANAS - SEPECH \\ Humanidades, Estado e desafios didático-científicos \\ Londrina, 27 a 29 de julho de 2016}

vezes, e na voz deles um pouco de nossa voz também aparecia, um grito que a gente não pode dar pelo outro, que a gente só pode dar na voz do outro, grito no grito alheio.

É dessa forma que encontramos um ponto chave entre a escrevivência e nossas experiências no cárcere: a sedução da arte que nos põe a dançar para convidar o outro a entrar em nosso território. Conceição Evaristo faz algo que ultrapassa o campo da ficção, mas sobre isso falaremos noutros fragmentos de nossa pesquisa. Por ora teremos em mente que assim como os rapazes da penitenciária tomavam para si algo do que encontravam na arte, seduzidos por aquele espaço artístico, aquele ritmo expressivo que abre outro mundo, ritornelo, também a ouvinte que reconta as histórias de Insubmissas lágrimas de mulheres deixa-se seduzir pela voz das mulheres que contam suas vidas. As histórias dessas mulheres abrem fresta no mundo e engolem a ouvinte, criam território coletivo onde é possível resistir a tantas adversidades que circundam, em especial, as vidas daqueles que estão, de algum modo, à margem da sociedade.

\section{CONSIDERAÇÕES FINAIS}

Através da arte e da sedução artística cria-se um espaço para resistir. Mas se é um espaço para resistir, a literatura de Evaristo não deveria conter menos violência? Não deveria ser um espaço de fuga? Por que frequentemente é retrato das violências que sofrem povo negro, mulheres e, em especial, mulheres negras? Será que é só retrato? Essas questões são o que norteiam parte do que refletimos em nossos trabalhos sequentes.

\section{REFERENNCIAS}

BACHELARD, Gaston. A Poética Do Espaço. Trad. Antônio de Padua Danesi. Martins Fontes: São Paulo, 1989.

BENJAMIN, Walter. O narrador. Considerações sobre a obra de Nikolai Leskov. In: . Magia e técnica, arte e política. São Paulo: Brasiliense, 1987.

DELEUZE, Gilles; GUATTARI, Félix. Mil Platôs: capitalismo e esquizofrenia, v. 4. São Paulo: 34, 1997.

EVARISTO, Conceição. Gênero e etnia: uma escre(vivência) de dupla face. In: SCHNEIDER, N. M. de B. M. L. (Org.). Mulheres no mundo: etnia, marginalidade e diáspora. João Pessoa: Ideia, 2005.

Insubmissas lágrimas de mulheres. Belo Horizonte: Nandyala, 2011.

FARIA JR., Miguel. Vinicius. Direção de Miguel Faria Junior. Brasil, 2005, 110 min, Documentário.

JESUS, Carolina Maria de. Quarto de Despejo. São Paulo: Lino Gráfica Editora. 1960. 


\section{SEMINÁRIO DE PESQUISA EM CIÊNCIAS HUMANAS - SEPECH \\ Humanidades, Estado e desafios didático-científicos \\ Londrina, 27 a 29 de julho de 2016}

LARSON, Christian. Valtari. Escrito e dirigido por Christian Larson; coreografia por Sidi Larbi Cherkaoui; cinematografia por Mattias Montero; design de figurino por Lydia Kovacs, produzido por Noreen Khan; dança por James O'Hara e Nicola Leahey; música por Sigur Rós. 2013. Disponível em: < http://sigurros.co.uk/valtari/videos/valtari-larson/> acesso em: 24 abr. 2016.

LIMA, Sheila Oliveira; MELO, Henrique Furtado. A leitura literária como revivência e ressignificação subjetiva de um aluno-detento. Revista Conexão UEPG, v. 9, n. 2, jul.dez. p. 312-323, 2013.

Leitura literária e vivência criativa no espaço carcerário. Via atlântica, v. 28, dez. p. 293-309, 2015.

PETIT, Michele. A arte de ler: ou como resistir à adversidade. Tradução de Arthur Bueno e Camila Boldrini. São Paulo: 34, 2009.

SIGUR RÓS. Valtari. United Kingdom, London: Parlophone, 2012, 54:36 min.

ZUMTHOR, Paul. Performance, recepção, leitura. Trad. Jerusa Pires Ferreira e Suely Fenerich. São Paulo: Cosac Naify, 2.ed., 2007. 